\title{
Spectrum Occupancy of Cellular Networks in Pakistan for Cognitive Radio - Measurements using Spectrum Analyzer
}

\author{
Sajjad Ali, Zhe Chen, and Fuliang Yin
}

\begin{abstract}
The spectrum scarcity is one of the major problems of wireless communication systems, and studies have shown that the static allocated licensed bands are under-utilized. Recently, the Cognitive Radio has emerged as a promising solution to diminish the spectrum scarcity, in which, an unlicensed user can utilize the licensed spectrum until its transmission does not interfere with the transmission of the licensed user. In this paper, the spectrum occupancy of all the GSM service providers of Pakistan is measured using the spectrum analyzer. The measurements of spectrum analyzer are in power spectral density versus frequency plots. Measurements result show that the GSM 900 band is clearly under-utilized, so a Cognitive Radio Network can be a potential solution to be employed in the cellular networks of Pakistan to diminish the spectrum scarcity and to optimize the spectrum utilization.
\end{abstract}

Index Terms-Cognitive radio, spectrum occupancy, spectrum analyzer, cellular networks.

\section{INTRODUCTION}

The spectrum scarcity has become an important issue in wireless communication systems due to expeditious increase in the wireless data traffic caused by the advent of smart phones, new value added services (VAS) and applications. The problem become worse in critical situations where wireless communication is used intensively, such as after a terrorist attack or in some massive emergency. At the same time, spectrum measurements of [1]-[4] have shown that the chunks of the static allocated spectrum are unused or under-utilized. Furthermore, the studies conducted by the Federal Communications Commission (FCC) show that the spectrum utilization varies from $15 \%-85 \%$ in the $0-6 \mathrm{GHz}$ band, thus resulting in spectrum wastage [5]. This spectrum wastage has forced the FCC to regularize the Cognitive Radio (CR), which was proposed by Mitola [6]. CR enables the optimistic use of under-utilized chunks of the spectrum by allowing (unlicensed) secondary users (SUs) to access the

Manuscript received May 8, 2015; revised August 17, 2015.This work was supported by National Natural Science Foundation of China (No.61172110, No.61172107), National High Technology Research and Development Program (“863”Program) of China, Specialized Research Fund for the Doctoral Program of Higher Education of China (200801410015), Major Projects in Liaoning Province Science and Technology Innovation of China (No.201302001), and Fundamental Research Funds for the Central Universities of China (No.DUT13LAB06).

The authors are with School of Information and Communication Engineering, Dalian University of Technology, Dalian 116203, China (e-mail:_ sajjad.ali@mail.dlut.edu.cn, zhechen@dlut.edu.cn, flyin@dlut.edu.cn). licensed spectrum while not interfering with the transmissions of the (licensed) primary users (PUs). Cognitive Radio Networks (CRN) is formed by interconnecting Cognitive Radios (CRs). A CR performs the spectrum sensing to scavenge the spectrum holes or white spaces and utilize these holes or spaces in an idealistic manner [7]-[14]. A spectrum hole or white space can be defined as a chunk of licensed spectrum band that can be utilized by SUs while not interfering with the PUs. Generally white spaces are divided into two categories: the temporal white spaces and the spatial white spaces. A temporal white space signifies that the spectrum band of interest is not utilized by the PU during the time of sensing; thus, this band can be utilized by CR users in the current time slot. A spatial white space exists when there is a primary transmission over the spectrum band of interest only in the restricted vicinity; thus, this band can be utilized by CR users well outside this vicinity [15].

The potential of CR to improve spectrum utilization is acknowledged in many countries and policies are being devised to access the fallow spectrum bands. However, it is imperative to comprehend the estimate of the spectrum occupancy accurately to exploit CRN commensurate to their potential and make the new policies successful. Spectrum survey or spectrum monitoring is the best tool to measure the spectrum occupancy and its usage pattern precisely. Several spectral surveys were conducted to survey different spectrum bands in different parts of the world [1]-[4], [16]-[20]. These spectral survey reports show the average power spectral density levels of received signals and utilized bandwidth over time in different spectrum bands.

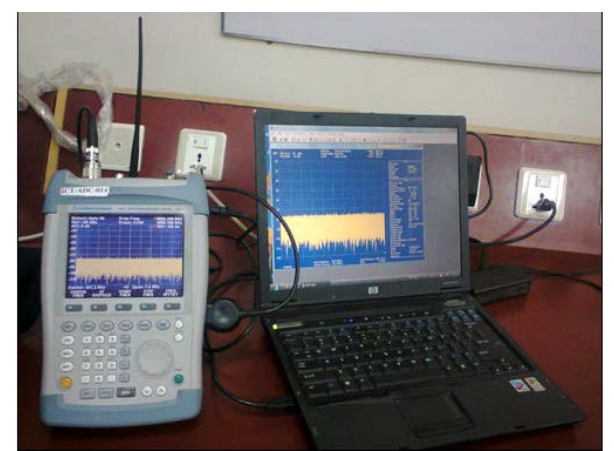

Fig. 1. Spectrum occupancy measurement setup.

In this paper, the spectrum occupancy measurement of all the GSM cellular operators of Pakistan is performed. The measurements are taken at Telecommunication Department (TD) of Mehran University of Engineering and Technology (MUET), Jamshoro on different days during university time. 
The results are presented in the form of power spectral density (PSD) for the each GSM cellular operator and its bandwidth utilization percentage. The measurements results are very useful for Pakistan Telecom Authority (PTA) to amend policies and encourage Pakistan GSM operators to deploy CRN to optimize spectrum utilization.

The rest of the paper is organized as follows. The measurement setup and method are presented in Section II. The measurement results are presented in Section III. In the end, some conclusions are drawn in Section IV.

\section{Measurement Setup And Method}

\section{A. Measurement Setup}

The spectrum occupancy measurements have been taken at different places in the TD including its roof top (2nd floor) using Rohde \& Schwarz FSH6 handheld spectrum analyzer. The frequency range of the spectrum analyzer (SA) is 100 $\mathrm{kHz}$ to $6 \mathrm{GHz}$. The spectrum occupancy measurement setup at one of the places is shown in Fig. 1, which depicts that a GSM 900 antenna is connected to SA via optical cable and SA is connected to a laptop via USB optical cable. The antenna specifications are given in Table I. The measurements have been taken for a weak during university time (08:00-15:00) on different times and each measurement has been taken for about 20 minutes. The Rohde \& Schwarz FSH view and MATLAB software are used to record and plot the spectrum occupancy measurements respectively.

TABLE I: ANTENNA SPECIFICATIONS

\begin{tabular}{|c|c|}
\hline \multicolumn{2}{|c|}{ Electrical specifications } \\
\hline Antenna model & AMXT-900-3 \\
\hline Frequency (MHz) & $824-960$ \\
\hline Bandwidth (MHz) & 136 \\
\hline Gain (dBi) & 3 \\
\hline VSWR & $\leq 2$ \\
\hline Impedance & $50 \Omega$ \\
\hline Polarization & Vertical \\
\hline Maximum input power (W) & 50 \\
\hline Input connector type & SMA male \\
\hline Mechanical specification \\
\hline Radome Color & Black \\
\hline Antenna height (mm) & 210 \\
\hline Antenna weight (g) & -40 to 60 \\
\hline
\end{tabular}

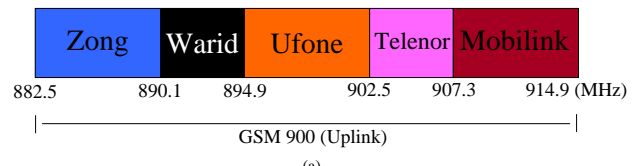

(a)

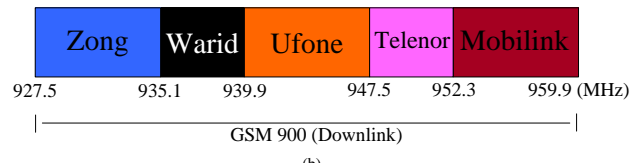

(b)

Fig. 2. Frequency allocation of the GSM 900 band in Pakistan.

\section{B. Cellular Operators of Pakistan}

There are five GSM cellular service providers in Pakistan; these are Mobilink, Ufone, Telenor, Warid and Zong. The frequency allocated in GSM 900 uplink and downlink bands to these operators is illustrated in Fig. 2 [21]. The SA settings for each GSM cellular service provider and GSM 900 band are shown in Table II.

\section{SPECTRUM OCCUPANCY RESUlTS AND DisCUSSION}

The results of the spectrum measurements are illustrated in average power spectral density (APSD) versus frequency. The APSD is calculated by averaging all the recordings collected during a seven-day measurement campaign for each band. The spectrum occupancy or utilized bandwidth is calculated by selecting a threshold level (a solid black line indicates threshold level in all figures) as shown in Fig. 3 Fig. 13. A $3 \mathrm{dBm}$ margin is used throughout this paper to select the threshold. The threshold is selected by adding 3 $\mathrm{dBm}$ in the minimum received power value. The minimum received power value and the selected threshold value of each measured spectral bands are listed in Table III. If the measured APSD of a certain frequency is above this threshold level, then that frequency is counted as occupied. The spectrum occupancy in percentage can be given as

$$
S O=\frac{P_{T}}{P} \times 100 \%
$$

where $P_{T}$ is the number of frequency measurement points exceeding the selected threshold level and $P$ is the total number of frequency measurement points in the measured spectrum band.

\section{A. Mobilink}

Mobilink launched its services in 1994 as the first GSM service provider in Pakistan. Recently, it has acquired 10 $\mathrm{MHz}$ spectrum band for 3G services and has initiated 3G services in major cities of Pakistan. Mobilink has the largest market share in Pakistani market today, that is $28 \%$, and its $3 \mathrm{G}$ subscriber share will be the largest in the country [22].

The spectrum measurement results of the Mobilink GSM 900 uplink and downlink spectrum bands are illustrated in Fig. 3 and Fig. 4, respectively. The spectrum occupancies of Mobilink uplink and downlink spectrum bands are $72.4252 \%$ and $74.0864 \%$, respectively. These results indicate that 4.0651 MHz spectrum band is unused out of the total 15.2 MHZ spectrum band of the Moblink GSM 900.

\section{B. Ufone}

Ufone commenced its GSM services in Pakistan on January 29, 2001. Currently, $5 \mathrm{MHz}$ spectrum band for 3G services has been auctioned to Ufone. Ufone launched its 3G services commercially throughout the Pakistan on May 23, 2014. The market share of Ufone is $18 \%$ among all the GSM service providers of Pakistan [23].

The spectrum measurement results of the Ufone GSM 900 uplink and downlink spectrum bands are illustrated in Fig. 5 and Fig. 6, respectively. The spectrum occupancies of Ufone uplink and downlink spectrum bands are 67.4419\% and 
$78.0731 \%$, respectively. These results indicate that 4.1408 $\mathrm{MHz}$ spectrum band is unused out of the total 15.2 $\mathrm{MHZ}$ spectrum band of the Ufone GSM 900.

TABLE II: THE SA SETTINGS FOR GSM SERVICE PROVIDERS AND GSM 900 BAND IN PAKISTAN

\begin{tabular}{|c|c|c|c|c|c|c|c|c|}
\hline \multicolumn{2}{|c|}{ SA parameters } & \multirow{2}{*}{ 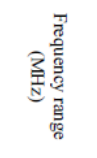 } & \multirow{2}{*}{ 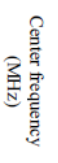 } & \multirow{2}{*}{ 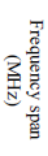 } & \multirow{2}{*}{ 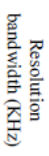 } & \multirow{2}{*}{ 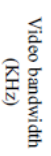 } & \multirow{2}{*}{ 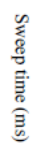 } & \multirow{2}{*}{ 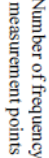 } \\
\hline \multicolumn{2}{|c|}{ GSM service providers } & & & & & & & \\
\hline \multirow{2}{*}{ Mobilink } & Uplink & $\begin{array}{c}907.3-914 \\
9 \\
\end{array}$ & 911.1 & 7.6 & $\begin{array}{c}20 \\
0 \\
\end{array}$ & $\begin{array}{c}20 \\
0 \\
\end{array}$ & $\begin{array}{c}10 \\
0\end{array}$ & 301 \\
\hline & Downlink & $\begin{array}{c}952.3-959 \\
9\end{array}$ & 956.1 & 7.6 & $\begin{array}{c}20 \\
0\end{array}$ & $\begin{array}{c}20 \\
0\end{array}$ & $\begin{array}{c}10 \\
0\end{array}$ & 301 \\
\hline \multirow{2}{*}{ Ufone } & Uplink & $\begin{array}{c}894.9-902 . \\
5\end{array}$ & $\begin{array}{c}898.4 \\
5\end{array}$ & 7.6 & $\begin{array}{c}20 \\
0\end{array}$ & $\begin{array}{c}20 \\
0\end{array}$ & $\begin{array}{c}10 \\
0\end{array}$ & 301 \\
\hline & Downlink & $\begin{array}{c}939.9-947 . \\
5 \\
\end{array}$ & 943.7 & 7.6 & $\begin{array}{c}20 \\
0\end{array}$ & $\begin{array}{c}20 \\
0\end{array}$ & $\begin{array}{c}10 \\
0\end{array}$ & 301 \\
\hline \multirow{2}{*}{ Telenor } & Uplink & $\begin{array}{c}902.5-902 . \\
3\end{array}$ & 904.9 & 4.8 & $\begin{array}{c}20 \\
0\end{array}$ & $\begin{array}{c}20 \\
0\end{array}$ & $\begin{array}{c}10 \\
0\end{array}$ & 301 \\
\hline & Downlink & $\begin{array}{c}947.5-952 \\
3\end{array}$ & 949.9 & 4.8 & $\begin{array}{c}20 \\
0\end{array}$ & $\begin{array}{c}20 \\
0\end{array}$ & $\begin{array}{c}10 \\
0\end{array}$ & 301 \\
\hline \multirow{2}{*}{ Warid } & Uplink & $\begin{array}{c}890.1-894 \\
9 \\
\end{array}$ & 892.5 & 4.8 & $\begin{array}{c}20 \\
0 \\
\end{array}$ & $\begin{array}{c}20 \\
0\end{array}$ & $\begin{array}{c}10 \\
0\end{array}$ & 301 \\
\hline & Downlink & $\begin{array}{c}935.1-939 \\
9\end{array}$ & 7.5 & 4.8 & $\begin{array}{c}20 \\
0\end{array}$ & $\begin{array}{c}20 \\
0\end{array}$ & $\begin{array}{c}10 \\
0\end{array}$ & 301 \\
\hline \multirow{2}{*}{ Zong } & Uplink & $\begin{array}{c}882.5-890 \\
1 \\
\end{array}$ & 6.3 & 7.6 & $\begin{array}{c}20 \\
0 \\
\end{array}$ & $\begin{array}{c}20 \\
0 \\
\end{array}$ & $\begin{array}{c}10 \\
0 \\
\end{array}$ & 301 \\
\hline & Downlink & $\begin{array}{c}927.5-935 \\
1 \\
\end{array}$ & 31.3 & 7.6 & $\begin{array}{c}20 \\
0 \\
\end{array}$ & $\begin{array}{c}20 \\
0\end{array}$ & $\begin{array}{c}10 \\
0\end{array}$ & 301 \\
\hline \multirow{2}{*}{ GSM 900} & Uplink & $\begin{array}{c}882.5-914 \\
9\end{array}$ & 898.7 & $\begin{array}{c}32 . \\
4\end{array}$ & $\begin{array}{c}20 \\
0\end{array}$ & $\begin{array}{c}20 \\
0\end{array}$ & $\begin{array}{c}50 \\
0\end{array}$ & $\begin{array}{c}150 \\
5\end{array}$ \\
\hline & Downlink & $\begin{array}{c}927.5-959 \\
5\end{array}$ & 943.5 & $\begin{array}{c}32 . \\
4\end{array}$ & $\begin{array}{c}20 \\
0\end{array}$ & $\begin{array}{c}20 \\
0\end{array}$ & $\begin{array}{c}50 \\
0\end{array}$ & $\begin{array}{c}150 \\
5\end{array}$ \\
\hline
\end{tabular}

TABLE III: Minimum Received Power VALUeS AND the Selected THRESHOLD VALUES OF EACH MEASURED SPECTRAL BAND

\begin{tabular}{|c|c|c|c|c|}
\hline \multicolumn{2}{|c|}{ GSM service providers } & Minimum received power value $(\mathrm{dBm})$ & Selected threshold value (dBm) & \\
\hline \multirow{2}{*}{ Moviluk } & Uplink & .95 .1439 & .92 .1439 & \\
\hline & Downlink & .91 .4471 & 88.4471 & \\
\hline \multirow{2}{*}{ Ufone } & Uplank & .95 .0451 & .92 .0451 & \\
\hline & Downlink & .93 .0632 & .90 .0632 & \\
\hline \multirow{2}{*}{ Telenor } & Uplink & 94.6394 & .91 .0394 & \\
\hline & Downlank & .92 .8812 & -89.8812 & \\
\hline \multirow{2}{*}{ Wand } & Uplink & .943000 & .913000 & \\
\hline & Downlink & .92 .6169 & -896169 & \\
\hline \multirow{2}{*}{ Zong } & Uplink & 94.6648 & -91.6648 & \\
\hline & Downlenk & .93 .7500 & .90 .7500 & \\
\hline \multirow{2}{*}{ GSM900 } & Uplink & .95 .1439 & $\left(\frac{-921439-920451-91.6394-913-91.6648}{5}\right.$ & $=-91.7586$ \\
\hline & Downlank & -93.62 & $\left(\frac{-88.4471-90.632-89.8812-89.6169-90.75}{5}\right.$ & $=.89 .7517$ \\
\hline
\end{tabular}

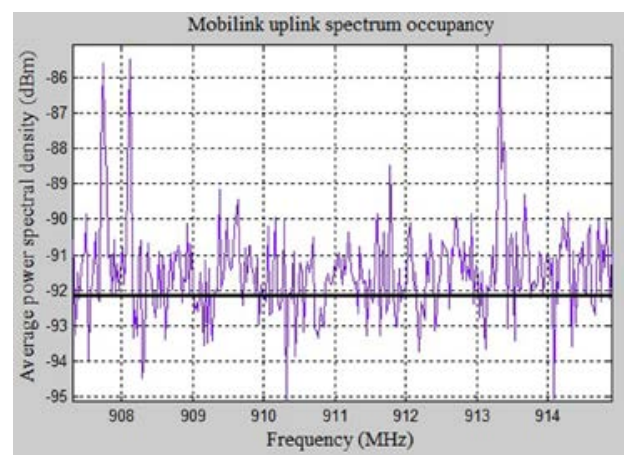

Fig. 3. Mobilink uplink spectrum occupancy measurements.

\section{Telenor}

Telenor started its GSM services in major cities of Pakistan on March 15, 2005. Recently, it has acquired $5 \mathrm{MHz}$ $3 \mathrm{G}$ spectrum band and has initiated its $3 \mathrm{G}$ services in major cities of Pakistan. Telenor has the second largest market share in Pakistani market today, which is $26 \%$ among all the GSM service providers of Pakistan [23].

The spectrum measurement results of the Telenor GSM 900 uplink and downlink spectrum bands are illustrated in
Fig.7 and Fig.8, respectively. The spectrum occupancies of Telenor uplink and downlink spectrum bands are $45.8472 \%$ and $45.1827 \%$, respectively. These results indicate that $5.2305 \mathrm{MHz}$ spectrum band is unused out of the total 9.6 MHZ spectrum band of the Telenor GSM 900.

\section{Warid}

Warid commenced its commercial GSM services in Pakistan on May 23, 2005. Warid is the only GSM operator that did not participate in the 3G spectrum auction that was held on April 23, 2014. Warid is intending to initiate 4G Long Term Evolution (LTE) services in Pakistan. Warid has been in talks with the Pakistan Telecommunication Authority (PTA), the telecom sector's regulatory body, for launching LTE service on its existing technology neutral license. The market share of Warid is 9\% among all the GSM service providers of Pakistan [23], [24].

The spectrum measurement results of the Warid GSM 900 uplink and downlink spectrum bands are illustrated in Fig.9 and Fig. 10, respectively. The spectrum occupancies of Warid uplink and downlink spectrum bands are 37.5415\% and $30.2326 \%$, respectively. These results indicate that 6.3468 MHz spectrum band is unused out of the total 9.6 MHZ spectrum band of the Warid GSM 900.

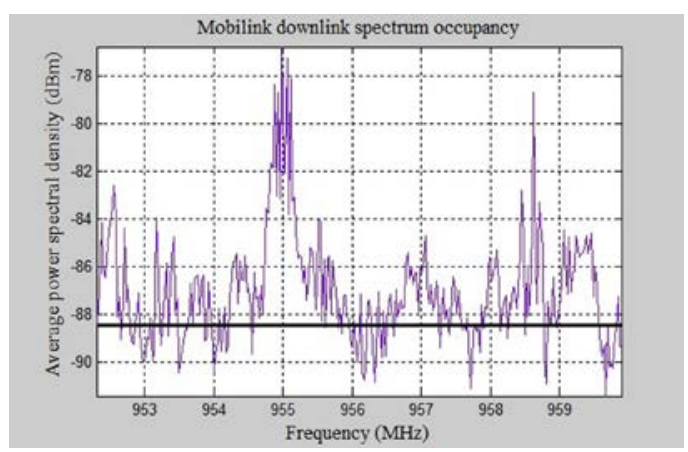

Fig. 4. Mobilink downlink spectrum occupancy measurements.

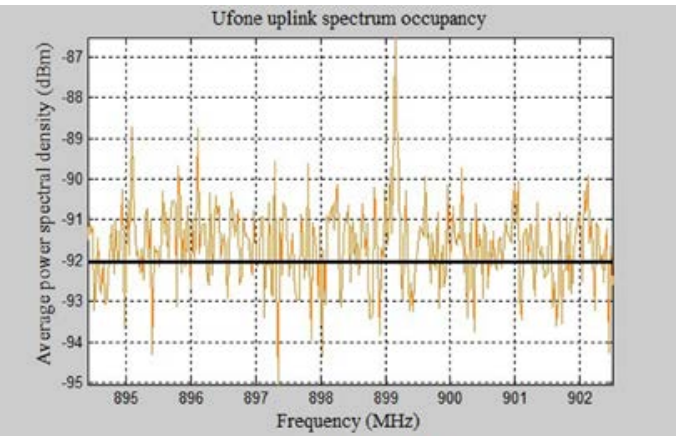

Fig. 5. Ufone uplink spectrum occupancy measurements.

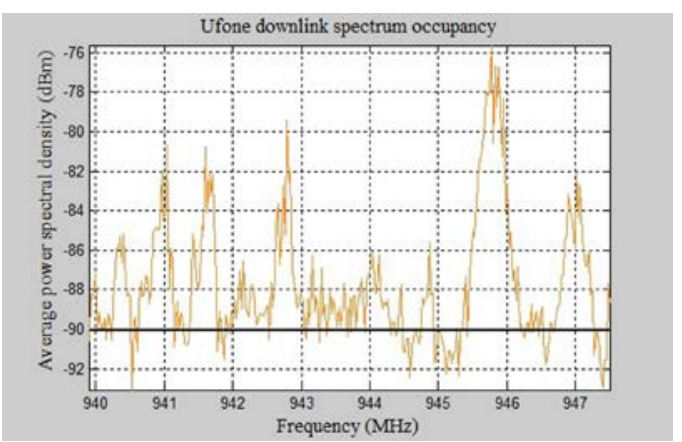

Fig. 6. Ufone downlink spectrum occupancy measurements. 


\section{E. Zong}

Zong began operations as Paktel by Cable \& Wireless in 1991. It was the first company granted a free license to carry out cellular phone services in Pakistan. It carried out Advanced Mobile Phone System (AMPS) services until 2004, when the company launched GSM services. Recently, it has acquired $10 \mathrm{MHz}$ each of $3 \mathrm{G}$ and $4 \mathrm{G}$ spectrum bands and became the Pakistan's first and only 4G cellular operator. It has the third largest market share in Pakistani market today, which is $19 \%$ among all the GSM service providers of Pakistan [23].

The spectrum measurement results of the Zong GSM 900 uplink and downlink spectrum bands are illustrated in Fig. 3 and Fig. 4, respectively. The spectrum occupancies of Zong uplink and downlink spectrum bands are 68.7708\% and $61.4618 \%$, respectively. These results indicate that 5.3023 $\mathrm{MHz}$ spectrum band is unused out of the total 15.2 MHZ spectrum band of the Zong GSM 900.

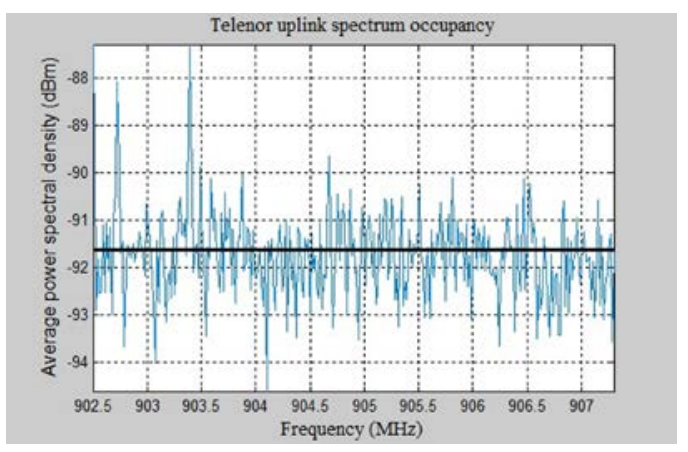

Fig. 7: - Telenor uplink spectrum occupancy measurements.

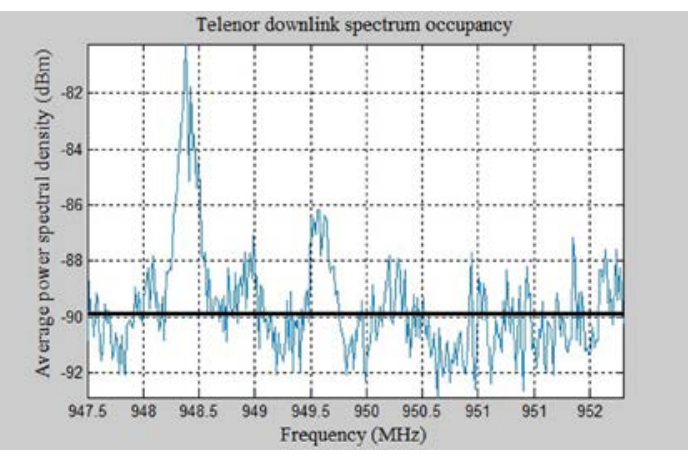

Fig. 8. Telenor downlink spectrum occupancy measurements.

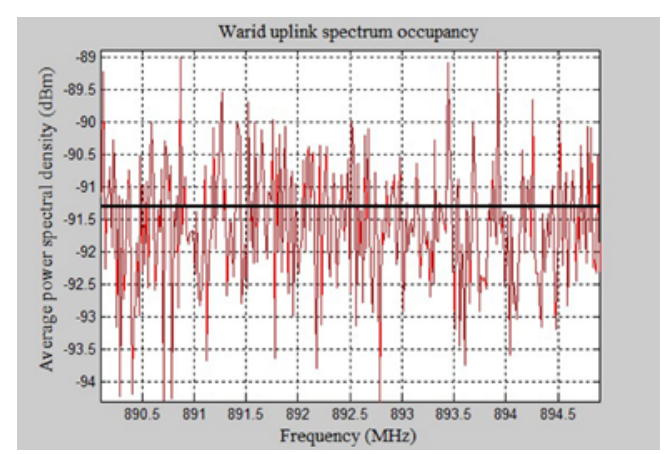

Fig. 9. Warid uplink spectrum occupancy measurements.

\section{F. GSM 900}

The spectrum measurement results of total GSM 900 uplink and downlink spectrums are illustrated in Fig. 12 and Fig. 13 respectively. The spectrum occupancies of GSM 900 uplink and downlink spectrums are $61.4618 \%$ and $60.5980 \%$, respectively. These results indicate that $25.2526 \mathrm{MHz}$ spectrum is unused out of the total $64.8 \mathrm{MHZ}$ spectrum of the GSM 900.

Spectrum occupancy and associated unused spectrum of all the GSM service providers and GSM 900 band are summarized in Table IV.

TABLE IV: A SUMMARY OF SPECTRUM OCCUPANCY AND UNUSED SPECTRUM

\begin{tabular}{|c|c|c|c|}
\hline \multicolumn{2}{|c|}{ GSM service providers } & $\begin{array}{c}\text { Spectrum occupancy } \\
(\%)\end{array}$ & $\begin{array}{c}\text { Unused spectrum } \\
(\mathrm{MHz})\end{array}$ \\
\hline \multirow{3}{*}{ Mobilink } & Uplink & 72.4252 & 2.0957 \\
\cline { 2 - 4 } & Downlink & 74.0864 & 1.9694 \\
\hline \multirow{3}{*}{ Ufone } & Uplink & 67.4419 & 2.4744 \\
\cline { 2 - 4 } & Downlink & 78.0731 & 1.6664 \\
\hline \multirow{2}{*}{ Telenor } & Uplink & 45.8472 & 2.5993 \\
\cline { 2 - 4 } & Downlink & 45.1827 & 2.6312 \\
\hline \multirow{3}{*}{ Warid } & Uplink & 37.5415 & 2.9980 \\
\cline { 2 - 4 } & Downlink & 30.2326 & 3.3488 \\
\hline \multirow{3}{*}{ Zong } & Uplink & 68.7708 & 2.3734 \\
\cline { 2 - 4 } & Downlink & 61.4618 & 2.9289 \\
\hline \multirow{2}{*}{ GSM 900 } & Uplink & 61.4618 & 12.4864 \\
\cline { 2 - 4 } & Downlink & 60.5980 & 12.7662 \\
\hline
\end{tabular}

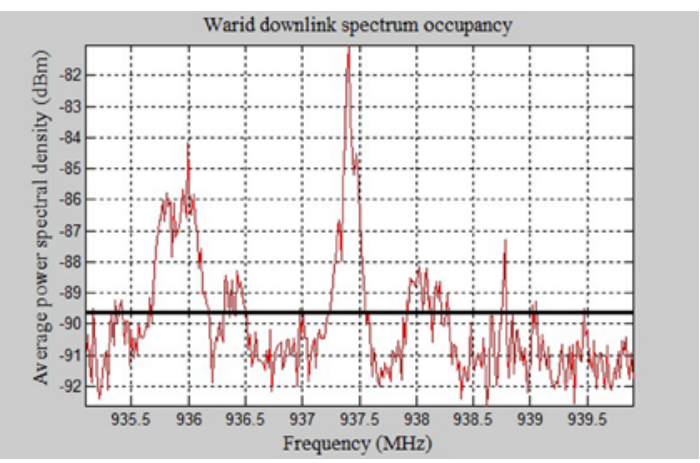

Fig. 10. Warid downlink spectrum occupancy measurements.

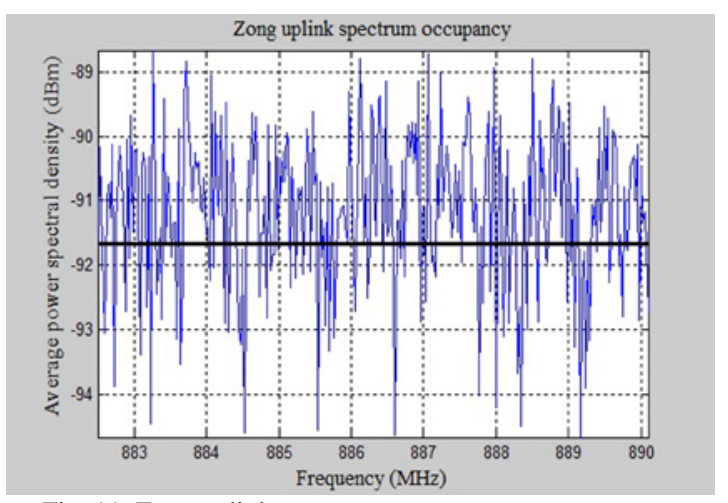

Fig. 11. Zong uplink spectrum occupancy measurements.

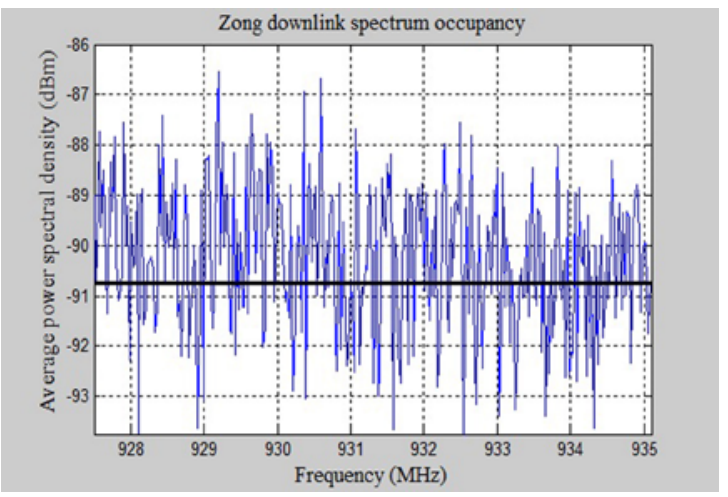

Fig. 12. Zong downlink spectrum occupancy measurements. 


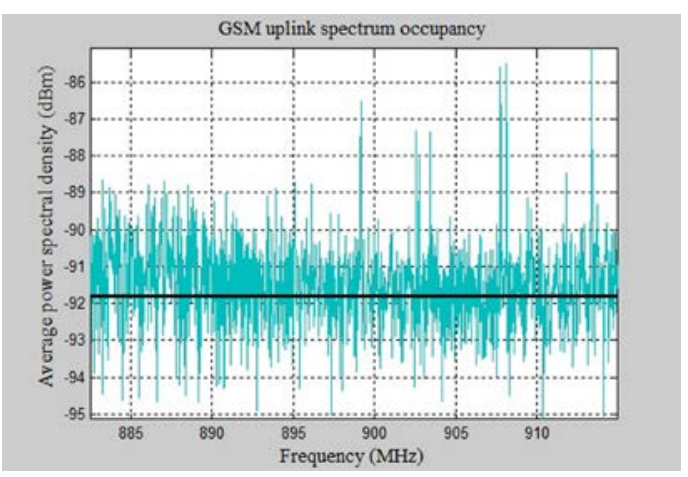

Fig. 13. GSM 900 uplink spectrum occupancy measurements.

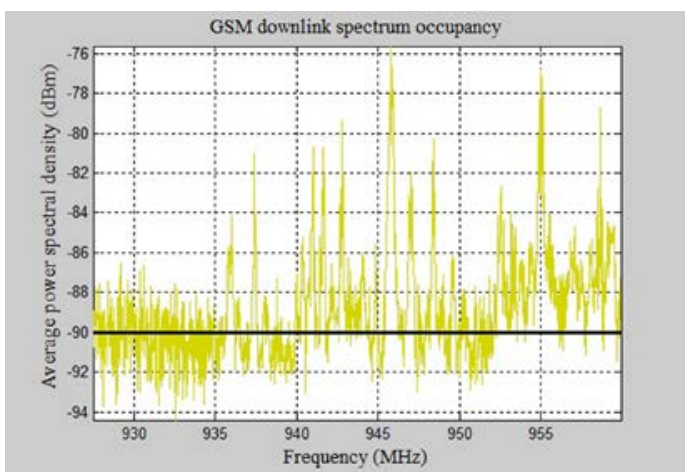

Fig. 14. GSM 900 downlink spectrum occupancy measurements.

Spectrum occupancy and associated unused spectrum of all the GSM service providers and GSM 900 band are summarized in Table I. The results have disclosed that 24MHz of GSM 900 spectrum band in Pakistan is unutilized spectrum that encourage cellular operators to deploy CRN to optimize spectrum utilization.

\section{CONCLUSION}

Spectrum occupancy measurements of all the GSM service providers of Pakistan are conducted in this paper. The spectrum measurement results show that $36 \%$ of the GSM 900 uplink and downlink allocated spectrum is unutilized.

Furthermore, spectrum measurement results confirm that $22.5 \%$ to $79.9 \%$ of bandwidth allocated to GSM service providers is unutilized. The bandwidth utilization of GSM service providers is not $100 \%$, beside the cellular users are growing fast in Pakistan. Therefore, CR can be the best solution to improve the spectrum utilization of the GSM 900 uplink and downlink allocated spectrum of Pakistan.

Spectrum scarcity is a major concern to wireless communication. Therefore it will be helpful to measure the spectrum occupancy of different static allocated licensed bands from time to time. This will give better idea about spectrum utilization, new directions about future spectrum allocations and help to serve more users in the limited spectrum.

\section{REFERENCES}

[1] M. Islam et al., "Spectrum Survey in Singapore: Occupancy Measurements and Analyses," Int. Conf. Cognitive Radio Oriented Wireless Networks and Communications (CrownCom), pp. 1-7, Singapore, May 15-17, 2008.

[2] V. Valenta et al., "Analysis of spectrum utilization in suburb environment - evaluation of potentials for cognitive radio,” IEEE Int.
Conf. Ultra-Modern Telecommunications and Workshops (ICUMT), pp. 1-6, S. Petersburg, Russia, Oct. 12-14, 2009.

[3] K. Qaraqe et al., "Empirical results for wideband multidimensional spectrum usage,” IEEE Int. Symp. Personal, Indoor and Mobile Radio Communications, pp. 1262-1266, Tokyo, Japan, Sep. 13-16, 2009.

[4] M. Wellens and P. Mahonen, "Lessons learned from an extensive spectrum occupancy measurement campaign and a stochastic duty cycle model,” IEEE Int. Conf. Testbeds and Research Infrastructures for the Development of Networks \& Communities and Workshops (Trident Com), pp. 1-9, Washington DC, USA, Apr. 6-8, 2009.

[5] FCC, "Spectrum Policy Task Force report,” ET Docket 02-155, Nov. 2002.

[6] J. Mitola, "Cognitive radio for flexible mobile multimedia communications," IEEE Int. Workshop Mobile Multimedia Communications (MoMuC), pp. 3-10, San Diego, CA, Nov. 15-17, 1999.

[7] G. Y. Chang et al., "Novel channel -hopping schemes for cognitive radio networks," IEEE Trans. Mobile Computing, vol.13, no.12, pp.407-421, 2014.

[8] X. Chen, H. Chen, and W. Meng, "Cooperative communications for cognitive radio networks - from theory to applications," IEEE Commun. Surveys \& Tutorials, vol.13, no.3, pp.1180-1192, Mar. 2014.

[9] A. Fanous, Y. E. Sagduyu, and A. Ephremides, "Reliable Spectrum Sensing and Opportunistic Access in Network-Coded Communications," IEEE J. Sel. Areas Commun., vol.32, no.3, pp.400-410, Dec. 2013.

[10] R. Han et al., "Harvestingspectrum access opportunity with directional antennas in indoor environments," IEEE Trans. Veh. Technol., vol.63, no.6, pp. 2964-2968, Jan. 2014.

[11] N. Rahimian et al., "On the probabilistic model for primary and secondary user activity for ofdma-based cognitive radio systems: spectrum occupancy and system throughput perspectives," IEEE Trans. Wireless Commun., vol. 13, no. 1, pp. 356-369, Dec. 2013.

[12] S. Stotas and A. Nallanathan, "Enhancing the capacity of spectrum sharing cognitive radio networks," IEEE Trans. Veh. Technol., vol. 60, no. 8, pp. 3768-3779, Aug. 2011.

[13] L. Zheng and C. W. Tan, "Maximizing sum rates in cognitive radio networks: convex relaxation and global optimization algorithms," IEEE J. Sel. Areas Commun., vol. 32, no. 3, pp. 667-680, Dec. 2013.

[14] A. G. Fragkiadakis, E. Z. Tragos, and I. G. Askoxylakis," A survey on security threats and detection techniques in cognitive radio networks," IEEE Commun. Surveys \& Tutorials, vol.15, no.1, pp.428-445, Jan. 2012.

[15] J. Ma, G. Y. Li, and B. H. Juang, "Signal processing in cognitive radio," Proc. IEEE, pp.805-823, vol. 97, no. 5, Apr. 2009.

[16] M. Wellens, J. Wu, and P. Mahonen, "Evaluation of spectrum occupancy in indoor and outdoor scenario in the context of cognitive radio,” presented at the Int. Conf. Cognitive Radio Oriented Wireless Networks and Communications (CROWNCOM), Orlando, FL, USA, 2007.

[17] R. I. C. Chiang, G. B. Rowe, and K. W. Sowerby, "A quantitative analysis of spectral occupancy measurements for cognitive radio," IEEE Veh. Technol. Conf. (VTC), pp. 3016-3020, Dublin, Ireland, Apr. 22-25, 2007.

[18] S. W. Ellingson, "Spectral occupancy at VHF: Implications for frequency - agile cognitive radios,” IEEE Veh. Technol. Conf. (VTC), Dallas, pp. 1379-1382, USA, 25-28 Sept. 2005.

[19] J. Do, D. M. Akos, and P. K. Enge, "L and S bands spectrum survey in the San Francisco Bay area,” IEEE Position, Location and Navigation Symposium (PLANS), pp. 566-572, Apr. 26-29, 2004.

[20] F. H. Sanders, "Broadband spectrum surveys in Denver, CO, San Diego, CA, and Los Angeles, CA: methodology, analysis, and comparative results," IEEE Int. Symposium Electromagnetic Compatibility, pp. 988-993, vol. 2, Denver, CO, Aug. 24-28,1998.

[21] Spectrum Occupancy State of Cellular Mobile Operators. [Online]. Available: http://www.pta.gov.pk/media/spec_cmo_pak_110413.pdf

[22] Mobilink. (March 2014). [Online]. Available: http://propakistani.pk/2014/03/21/mobilink-to-get-largest-3g-ready-ne twork-by-july-2014/

[23] Farooq Baloch. (May 2014). Telecommunications: Zong overtakes Ufone a CMOs' market share changes. [Online]. Available: http://tribune.com.pk/story/703791/telecommunications-zong-overtak es-ufone-as-cmos-market-share-changes/

[24] Jawwad Rizvi. (April 2014). Warid plans to launch LTE technology. [Online].

Available: http://www.thenews.com.pk/Todays-News-3-244787-Warid-plans-tolaunch-LTE-technology 


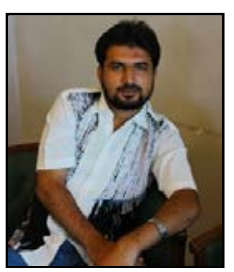

Sajjad Ali received his B.E. degree in Telecommunication Engineering and the M.E. degree in Communication Systems Networks from Mehran University of Engineering \& Technology (MUET), Jamshoro, Pakistan, in 2007 and 2011, respectively. He joined Telenor Pakistan as O\&M engineer in 2007. He then joined the Department of Telecommunication Engineering, MUET, as a lab-lecturer in 2008, and became Assistant Professor in 2011. He is currently doing his Ph.D. in Dalian University of Technology (DUT), Dalian, China. His research interests are in the field of digital signal processing and broadband wireless communications.

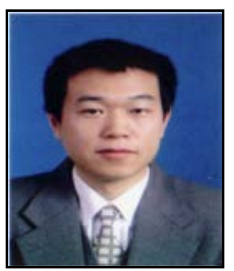

Zhe Chen received his B.S. degree in Electronic Engineering, the M.S. degree in signal and information processing, and the Ph.D. degree in Signal and information processing from Dalian University of Technology (DUT), Dalian, China, in 1996, 1999 and 2003, respectively. He joined the Department of Electronic Engineering, DUT, as a lecture in 2002, and became an associate professor in 2006. His research interests include digital signal processing, speech processing, image processing, and broadband wireless communication.

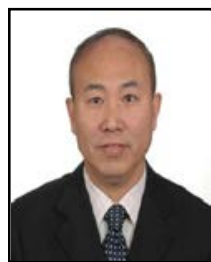

Fuliang Yin received his B.S. degree in electronic engineering and the M.S. degree in communications and electronic systems from Dalian University of Technology (DUT), Dalian, China, in 1984 and 1987, respectively. He joined the Department of Electronic Engineering, DUT, as a lecturer in 1987 and became an associate professor in1991. He has been a Professor at DUT since 1994, and the dean of the School of Electronic and Information Engineering of DUT from 2000 to 2009. His research interests include digital signal processing, speech processing, image processing, and broadband wireless communication. 